Journal of Social Sciences 4 (2): 88-97, 2008

ISSN 1549-3652

(C) 2008 Science Publications

\title{
Multivariate Modelling of the Canary Islands Banana Output. The Role of Farmer Income Expectation
}

\author{
Concepción González-Concepción, María Candelaria Gil-Fariña and Celina Pestano-Gabino \\ Department of Applied Economics, Faculty of Economics and Business Administration, \\ University of La Laguna, Campus of Guajara, s/n, 38071 La Laguna, \\ Tenerife, The Canary Islands, Spain
}

\begin{abstract}
The EU is the world's largest importer of bananas and the only major managed market in the international banana trade. Spain is the main banana producer within the European Union (EU), followed by France and Portugal. In all these countries the fruit is grown in overseas islands situated in tropical or sub-tropical areas and bananas are a pillar of the economic, social and environmental balance of these regions. Spanish production comes from the Canary Islands, an insular environment located in the Atlantic Ocean more than $1000 \mathrm{~km}$ south of the Iberian Peninsula and near the northwest coast of Africa. In the context of high production costs and strong competition from Latin American imports, the compensatory aid that local farmers have been receiving from the EU since 1993 has helped the archipelago to maintain its agricultural position while constituting a main support from an economic, social and landscaping standpoint. This research analyses the Canary Islands banana output evolution through the use of certain multivariate dynamic models that consider the influence of past production costs, past farmer income and future expectations, including a sensitivity analysis. We consider annual data time series on production, perceived prices and production costs for the period 1938-2002. Model predictions are contrasted using data for the period 2003-2006, thus spanning a wide period of time that includes key points such as the 1993 reform and the introduction of the 2006 reform. The empirical work highlights, as do all EU norms, the importance of maintaining adequate farmer income expectations to assure subsistence banana production.
\end{abstract}

Key words: Economics, multivariate time models, rational approximation, banana, production, income, cost, income expectations

\section{INTRODUCTION}

The social, political and economic importance of the banana market shapes many of the decision-making policies of the $\mathrm{EU}$, where the volume of regulations over recent decades concerning Farming Integration, and specifically of the banana market, has called attention to the concerns over this market. More recently, the topic of subsidies for domestic production is being addressed in an effort to adapt the market to globalization and to open it up to Latin American countries, the dollar area and ACP, as well as to try to balance the interests of all those involved (producers, exporters, importers and consumers).

Relevant scientific research has also tried to shed some light on the issue, in particular on the implications that certain deregulatory or anti-protectionist measures in the EU market would have economically both within the EU and elsewhere.

A search of scientific references involving bananas in the ranking of the Journal Citation Reports (Science Citation Index and Social Science Citation Index) reveals over five thousand results. Such references are evidence of continued scientific interest, especially starting in the 1990s, following the establishment of European subsidies intended to offset losses in production income.

Among these references, however, there is a shortage of works that specifically address the social, environmental and/or economic/financial aspects involved. Particularly lacking is the use of quantitative tools to analyse econometric models, statistical data, types of competition in the market, supply-demand elasticity and so on ${ }^{[1-7}$ among others] . This relative dearth

Corresponding Author: Concepción González-Concepción, Department of Applied Economics, Faculty of Economics and Business Administration, University of La Laguna, Campus of Guajara, s/n, 38071 La Laguna, Tenerife, The Canary Islands, Spain Tel: 34922317029 Fax: 34922317204 
may be due to, as stated $\mathrm{in}^{[28]}$, the extreme lack of available data, particularly as concerns prices along the supply chain, which constitutes a decisive parameter that affects the result of every analysis.

Specifically, few studies exist concerning the situation of the banana crop in the Canary Islands (www.mapa.es).

The seven islands that make up the Canary Islands (The Canaries) are a minuscule insular environment with a surface area of $7,456 \mathrm{~km}^{2}$. Their volcanic origin, the rocky terrain and their special position in the Atlantic Ocean have given the islands a unique character which has been shaped, among other factors, by the banana crop, resulting in a balanced setting where the black of the volcanic lava contrasts with the green fields, especially in the north side of the most westerly islands. The resulting landscape is unlike any other found in the world.

The traditional banana variety grown in the Canaries is the dwarf banana, brought from Asia in the mid nineteenth century. The fruit is smaller, sweeter and has a more intense flavour than the varieties produced in Latin America and the Caribbean.

The banana crop is the leading farming activity in the Islands and ranks second economically only to tourism, to which it is closely linked for visually aesthetic and environmental reasons, among others.

Worldwide banana production in 2002 was estimated at 65 million tons (www.unctad.org and www.fao.org), with India as the leading producer at $20 \%$ (although only $20 \%$ of worldwide production is earmarked for export).

Spain, with the Canarian production, is the main banana producing area within the $\mathrm{EU}$, and the main destination for the Canarian producers is the Spanish peninsular market. However, community banana production is limited, accounting for $1.1 \%$ of worldwide production, with the Canary Islands production representing only about $0.7 \%$ of worldwide production, which still places it above countries such as Haiti, Angola, Madagascar, South Africa, Australia, Kenya or Argentina.

The EU relies on local growers for around a fifth of its banana needs, so the rest must be imported. According to EUROSTAT, 4 million tons of bananas were consumed in the EU in 2002, a number which has declined in recent years. The majority $(63 \%)$ was provided by Latin American countries (the world's largest banana exporters are Ecuador, Costa Rica and Colombia with quotas of around 25, 21 and $20 \%$ of the total amount, respectively), $18 \%$ by European colonies in Africa, the Caribbean and Pacific (ACP) and 19\% by the EU (mainly local producers from the Canary
Islands, representing $52 \%$ of the quota, followed by Martinique and Guadeloupe (French territories), Madeira (Portugal) and Laconia (Greece)). In 2004, before the last reform, the Canarian supply to the EU was exceeded by only three non-EU countries: Ecuador, Costa Rica and Colombia,

The banana, which is one of the most important crops in the Canary Islands in terms of cultivated area, represents nearly $20 \%$ of all farming land. Tenerife is the largest island and possesses the greatest number of cultivated hectares (approx. 43\%). Its northern region represents more than $50 \%$ of the banana area in Tenerife. This crop accounts for some $43 \%$ of total agricultural production $(955,624$ tons), followed by the tomato $(27 \%)$, potato $(9 \%)$ and grapes $(2 \%)$. These four crops make up $82 \%$ of the agricultural production and are all located in the four western islands.

Banana production value in 2002, for example, represented 111.883 million euros, which is $21 \%$ of the output value in the agricultural subsector and $16 \%$ of the agrarian production value, including the cattle subsector.

EU productivity per hectare is one of the highest in the world: so the Canaries produce 44 tons/ha compared to Honduras with 20 tons/ha, despite the fact that banana production, as well as other agricultural activities in the islands, is handicapped by the remoteness, insularity, small size and difficult topography.

The role of banana cultivation in the Canary archipelago has a compounding effect on the islands' economic development and as such, is extremely relevant when the economic significance in terms of production, income and employment are considered. Thirty percent of the agricultural work-force is employed in this sector.

The leading role of the banana and its social significance goes beyond economic indicators, not only for a considerable cross-section of the local population, but also from a social, cultural and ecological standpoint. It is a leading factor in preventing rural emigration and maintaining a landscape which is fundamental for attracting tourism and for stopping erosion and urban growth in agricultural land.

Banana markets, however, have historically been conditioned by strong competition among multinational corporations, which have been increasing their market share. These companies are strong enough to set lower selling prices, resulting in unprofitable and unfeasible fruit shipments from the Canary Islands in many cases.

Ever since the establishment of the Common Market Organisation for Bananas (CMOB) in 1993, Latin American imports have been increasing. The geographical conditions in these countries are more 
suitable for banana production. Conditions such as plantation size, economic and social structures (leading to low labour costs) and plentiful water-bearing resources are just some of them.

Consequently, the competitiveness of Canarian bananas has been seriously affected by banana imports from the dollar area. The most recent decades have also seen changes in market inputs (labour force, water and fertilisers) accompanied by structural changes intended to benefit tourism in the Canary Islands.

This setting of high production costs and strong competition has created a dependence by local farmers on the compensatory aid that they have been receiving from the EU since 1993 per kilogram marketed. This mechanism serves to guarantee the farmer's income and preserves the banana as a main support from an economic, social, cultural and landscaping standpoint in the Canary Islands. However, in November 2005, tropical storm Delta damaged a total acreage of 6020 ha of Canarian banana plantations, turning 2005 into one of the worst years for agriculture in the archipelago in the last decade. Banana production was about 75 million kilos less than in 2004 and the compensatory aid to local producers diminished considerably.

Moreover, starting in early 2006, the regime for the banana market protection adopted the tariff only system, increasing banana imports and substituting the tariff- quota system and licensing regime.

In this first year of the EU's tariff-only regime for bananas, EU imports increased by $12.3 \%$ as the EU's own banana output dropped by $1 \%$ to just $13 \%$ of overall supply.

However, the excise level applied under the EC's tariff only system, which has been set at Euro 176 per tonne, appears to be too low and does not help to maintain this strategic sector in the European producer areas, as is the case with the Canary Islands.

This research focuses on studying multivariate time series models for the Canarian banana output. Considering data for the period 1938-2002, we show the predictive ability performance of the farmer's income (including the European subsidies) in the banana output evolution. Production costs (water and fertilisers) are also studied and their relation to other variables is empirically illustrated. Empirical findings using the SCA package ${ }^{[8]}$ confirm the relevance of the income variable to explain banana output evolution. Therefore, income expectation is considered in order to carry out a sensitivity analysis of the banana output from the perspective of non-causal time series models ${ }^{[9]}$. The prices referenced in this paper are exclusively those received by the farmer (income) from the market. Given their confidential nature, it was impossible to consider supply chain prices in our research.

In keeping with the dynamics of European regulations, the empirical results highlight both the importance and the difficulty of establishing conditions for opening up the markets which take into account all aspects involved. It particularly calls attention to the consequences of this action for EU producers and consumers alike.

\section{SOME METHODS OF RATIONAL CHARACTERIZATION IN MULTIVARIATE TF MODELS. THEORETICAL REMARKS}

A TF model with expectations or a non-causal TF model ${ }^{[9]}$ for a stationary process with a one-dimensional $\mathrm{y}_{\mathrm{t}}$ and $\mathrm{n}$-dimensional $\mathrm{x}_{\mathrm{t}}^{*}, \mathrm{x}_{\mathrm{t}}^{* *}$ takes the following form:

$$
\mathrm{y}_{\mathrm{t}}=\sum_{\mathrm{i}=1}^{\mathrm{n}} \sum_{\mathrm{j}=0}^{\infty} \mathrm{v}_{\mathrm{ij}}^{*} \mathrm{x}_{\mathrm{it}-\mathrm{j}}^{*}+\sum_{\mathrm{i}=1}^{\mathrm{n}} \sum_{\mathrm{j}=0}^{\infty} \mathrm{v}_{\mathrm{ij}}^{* *} \mathrm{x}_{\mathrm{it}+\mathrm{j}}^{* *}+\mathrm{N}_{\mathrm{t}} ; \mathrm{N}_{\mathrm{t}}=\frac{\theta_{\mathrm{q}}(\mathrm{B}) \vartheta_{\mathrm{Q}}\left(\mathrm{B}^{\mathrm{s}}\right)}{\Theta_{\mathrm{p}}(\mathrm{B}) \Phi_{\mathrm{P}}\left(\mathrm{B}^{\mathrm{s}}\right)} \mathrm{a}_{\mathrm{t}}
$$

The output $\mathrm{y}_{\mathrm{t}}$ is explained by two components: one systematic, described by the input variables $x_{i t}^{*}(i=1, \ldots n)$ (real data) and $\mathrm{x}_{\mathrm{it}}^{* *}(\mathrm{i}=1, \ldots, \mathrm{n})$ (expectations) and a nonsystematic one described for a multiplicative ARMA process $(p, q) x(P, Q)_{s}$ with $a_{t} \sim N\left(0, \sigma^{2}\right)$. A one-way causal dynamic relationship $x_{t}^{*}, x_{t}^{* *} \rightarrow y_{t}$ is assumed.

A closer form can be expressed as:

$$
\mathrm{y}_{\mathrm{t}}=\sum_{\mathrm{i}=1}^{\mathrm{n}} \mathrm{v}_{\mathrm{i}}(\mathrm{B}) \mathrm{x}_{\mathrm{it}}+\mathrm{N}_{\mathrm{t}}
$$

where, $\quad x_{i, t-j}=x_{i, t-j}^{*}$ if $j \geq 0, x_{i, t-j}^{* *}$ if $j<0 \quad$ and $v_{i}(B)=\sum_{j=-\infty}^{\infty} v_{i j} B^{j}$ represents the IRF, that is, the series of weights evaluated in $\square$.

We generalise the proposal given in $^{[10]}$ for causal models to compute the estimated weights $\hat{\mathrm{v}}_{\mathrm{ij}}$ for each input variable and the matrix covariance by using Ordinary Least Squares or maximising the Likelihood Function. The lag and lead structures can be approximated by means of a finite number of terms $\left(\mathrm{m}_{\mathrm{i}}<0\right.$ and $\left.\mathrm{k}_{\mathrm{i}}>0\right)$ :

$$
\mathrm{y}_{\mathrm{t}} \cong \sum_{\mathrm{i}=1}^{\mathrm{n}} \sum_{\mathrm{j}=\mathrm{m}}^{\mathrm{k}_{\mathrm{i}}} \hat{\mathrm{v}}_{\mathrm{ij}} \mathrm{x}_{\mathrm{i}, \mathrm{t}-\mathrm{j}}+\mathrm{N}_{\mathrm{t}}^{*}
$$

This yields consistent parameter estimations without any previous knowledge of the noise structure. Other statistical properties justify its use as reliable initial values in more efficient methods, generally of the 
non-linear iterative type that offer final estimations of the model parameters.

Starting from the sequence of relative weights $\hat{\eta}_{i} \equiv\left(\hat{\eta}_{i j}\right)_{j \in \square}, \quad \hat{\eta}_{i j}=\frac{\hat{v}_{i j}}{\hat{v}_{i, \max }}, \quad \hat{v}_{i, \max }=\max _{j}\left|\hat{v}_{i j}\right|, \quad$ some alternative techniques to characterise a TF model with expectations can be obtained. It can be expressed in a finite form as:

$$
\mathrm{y}_{\mathrm{t}}=\sum_{\mathrm{i}=1}^{\mathrm{n}} \frac{\mathrm{W}_{\mathrm{i}}(\mathrm{B})}{\Psi_{\mathrm{i}}(\mathrm{B})} \mathrm{x}_{\mathrm{it}}+\frac{\theta_{\mathrm{q}}(\mathrm{B}) \vartheta_{\mathrm{Q}}\left(\mathrm{B}^{\mathrm{s}}\right)}{\Theta_{\mathrm{p}}(\mathrm{B}) \Phi_{\mathrm{p}}\left(\mathrm{B}^{\mathrm{s}}\right)} \mathrm{a}_{\mathrm{t}}
$$

where, $\mathrm{B}$ is the back-shift operator, $\mathrm{W}_{\mathrm{i}}(\mathrm{B})=\omega_{\mathrm{i}, \mathrm{p}_{\mathrm{i}}+\mathrm{a}_{\mathrm{i}}} \mathrm{B}^{\mathrm{p}_{\mathrm{i}}+\mathrm{a}_{\mathrm{i}}}+\ldots+\omega_{\mathrm{i}, \mathrm{s}_{\mathrm{i}}+\mathrm{b}_{\mathrm{i}}} \mathrm{B}^{\mathrm{s}_{\mathrm{i}}+\mathrm{b}_{\mathrm{i}}} \quad$ and $\Psi_{\mathrm{i}}(\mathrm{B})=\delta_{\mathrm{i},-\mathrm{d}_{\mathrm{i}}} \mathrm{B}^{-\mathrm{d}_{\mathrm{i}}}+\ldots+\delta_{\mathrm{ir}_{\mathrm{i}}} \mathrm{B}^{\mathrm{r}_{\mathrm{i}}}$ are Laurent Polynomials, $\mathrm{p}_{\mathrm{i}}, \mathrm{s}_{\mathrm{i}} \in \square, \mathrm{d}_{\mathrm{i}}, \mathrm{r}_{\mathrm{i}} \in \square, \mathrm{a}_{\mathrm{i}}$ and $\mathrm{b}_{\mathrm{i}}$ the lead and lag effects on $\mathrm{y}_{\mathrm{t}}$ from changes in $\mathrm{x}_{\mathrm{it}}$.

This formulation generalises the causal TF model that only considers real data for the inputs and no expectations.

Several methods have been proposed based on algorithms related to Padé and Padé-Laurent Approximation $^{\text {[10-21 among others] }}$, which help identify the polynomial orders in the TF model. Here, we consider the T-table method and the generalised epsilonalgorithm, both of them proposed by ${ }^{[9]}$. These methods are the generalisation of the corner method and the epsilon-algorithm, respectively, to classical TF models ${ }^{[10,15,17 \text { among others] }}$.

Some adequate transformations in the sequence of relative weights may be necessary to avoid computational instability in specific cases.

\section{MULTIVARIATE CAUSAL TF MODELS: PRODUCTION, INCOME AND COST}

A three-dimensional relationship between Production, Income and Average Production Cost is studied, taking data for the period 1938-2002 in the Canary Islands. Data on production and farmer income series were taken from ${ }^{[22-24]}$. Official data on production costs were not available. Therefore, water and fertiliser data provided by three representative private properties in the north of Tenerife were considered. Linear interpolation was used to extend the sample size ${ }^{[25]}$, so only the odd data sets in the series correspond to the actual data. Also, some necessary logarithmic and firstdifference transformations were used to obtain a more homogenous variance in the data and to guarantee stationary processes.
Let us define the following variables in time $\mathrm{t}$ :

- $\mathrm{z}_{\mathrm{t}}=\ln \operatorname{Prod}_{\mathrm{t}}-\ln \operatorname{Prod}_{\mathrm{t}-1} \equiv(1-\mathrm{B}) \ln \operatorname{Prod}_{\mathrm{t}}$, where, for $\mathrm{t}$ odd, $\operatorname{Prod}_{t}$ is banana Production in thousands of tons and, for $t$ even, $\operatorname{Prod}_{t}$ is the result of the interpolation between $\operatorname{Prod}_{\mathrm{t}-1}$ and $\operatorname{Prod}_{\mathrm{t}+1}$; Similarly

- $\mathrm{x}_{\mathrm{t}}=\operatorname{lnI}_{\mathrm{t}}-\operatorname{lnI}_{\mathrm{t}-1} \equiv(1-\mathrm{B}) \operatorname{lnI}_{\mathrm{t}}$ where, for $\mathrm{t} \operatorname{odd}_{2} \mathrm{I}_{\mathrm{t}}$ is the farmer indexed Income or amount received by the farmer $(\mathrm{ptas} / \mathrm{kg}) \quad(\mathrm{ptas}=$ pesetas, the Spanish currency before the euro) (Index $1996=100$ ) and, for $t$ even, an interpolated value

- $\quad \mathrm{y}_{\mathrm{t}}=\operatorname{lnCost}_{\mathrm{t}}-\ln \operatorname{Cost}_{\mathrm{t}-1} \equiv(1-\mathrm{B}) \ln \operatorname{Cost}_{\mathrm{t}}$, where, for $\mathrm{t}$ odd, Cost $t_{t}$ is the indexed Average Cost $(\mathrm{ptas} / \mathrm{kg})($ Index $1996=100)$ and for $\mathrm{t}$ even, an interpolated value

- $\quad \mathrm{s}_{\mathrm{t}}=\operatorname{lnBenef}_{\mathrm{t}}-\operatorname{lnBenef} \mathrm{f}_{\mathrm{t}-1} \equiv(1-\mathrm{B}) \ln$ Benef $_{\mathrm{t}}$, where, for $\mathrm{t}$ odd, Benef $\mathrm{f}_{\mathrm{t}}=\mathrm{I}_{\mathrm{t}}-$ Cost $_{\mathrm{t}}$ is the indexed Profit $($ ptas $/ \mathrm{kg})($ Index $1996=100)$ and for $\mathrm{t}$ even, an interpolated value

A bivariate causal TF model for production and income: Previous results on the relationship between Production and Income can be found in ${ }^{[18]}$.

The causal model performance of farmer sensitivity to the European payments is studied in a single-input, single-output causal TF model relating Production and Income.

The Cross Correlation Function (CCF) and the covariance matrix confirm a one-way causal dynamic relationship from the input to the output.

A finite order representation for the IRF $v(B)$ based on available sample data could be given by using the numerical methods mentioned before.

The identification stage for the lag polynomial orders corresponds to the theoretical modelling. Parameter estimation is carried out by means of the maximum likelihood method (implemented in the SCA package) once the model has been tentatively identified.

Once the Impulse Response Function v(B) has been estimated, the corner method and the study of the noise term provide the next causal model:

$$
\mathrm{z}_{\mathrm{t}}=0.1658_{(4.98)} \mathrm{B}^{4} \mathrm{x}_{\mathrm{t}}+\left(1+0.99285_{(-24.46)} \mathrm{B}\right) \mathrm{a}_{\mathrm{t}}
$$

where, the income due to the market price and the compensatory aid have been included in the input variable and $\mathrm{a}_{\mathrm{t}}$ is a Gaussian white noise process.

This model basically shows the influence of the payments received by the farmer in the three years prior to crop harvest and marketing.

Fig. 5 shows that while the resulting causal model is adequate for fitting available data, it fails to provide a satisfactory response in terms of predictive performance. The model was fitted using data for the period 1938-1992. The subsequent data from 1993, 
when farmers began to receive the compensatory aid, were used to obtain the output predictions. Output predictions from 1993 cannot show the real evolution of banana output, which is why we investigated the effect of other production variables, considering that when the production is planned, the farmer takes into account not only his previous income but other important variables as well, such as the costs associated with production and/or the income he hopes to receive for his work in future years.

Next, we present models that consider a variable to account for production cost in three different ways, and we consider certain non-causal models which include the farmer's expectations on his future income.

Including the cost (i): a bivariate causal TF model for production and profit: The next causal TF model relating Production and Profit uses data for the period 1938-2003. We consider $\mathrm{z}_{\mathrm{t}}=\alpha+\sum_{\mathrm{i}=0}^{13} \mathrm{v}_{\mathrm{i}} \mathrm{s}_{\mathrm{t}-\mathrm{i}}+\mathrm{N}_{\mathrm{t}}$.

Since the quantitative relationship between Production and Profit would have to be simpler to include just two variables, the latter is considered as the difference between Income (including the market price and the compensatory aid) and the Average Production Cost (water and fertilisers are the items considered).

A one-way causal dynamic relationship $s_{t} \rightarrow z_{t}$ can be deduced by studying the Cross Correlation Function (CCF) and the covariance matrix.

The Impulse Response Function $\mathrm{v}(\mathrm{B})$ was estimated using pre-1995 data (115 observations). In this case the corner table cannot clearly exhibit a rational pattern for the deterministic component.

Once non-significant parameters are deleted, the causal model obtained is similar to (1), that is:

$$
\mathrm{z}_{\mathrm{t}}=0.1201_{(5.22)} \mathrm{B}^{4} \mathrm{~s}_{\mathrm{t}}+\left(1+0.9301_{(-26.48)} \mathrm{B}\right) \mathrm{a}_{\mathrm{t}}
$$

Forecasts can be obtained from 1995 by retaining the final observations for the purpose of a post-sample check of forecasting performance.

Two types of forecasted values were generated: the first, from the last observation of the fitted model, and the second, a stepwise model in which the starting point of the current forecast is generated in the previous step.

Although outlier detection produced three unusual observations (innovational outliers) in 1955, 1973 and 1980, the resulting model was quite similar to the previous one, that is:

$$
\mathrm{z}_{\mathrm{t}}=0.1004_{(5.51)} \mathrm{B}^{4} \mathrm{~s}_{\mathrm{t}}+\left(1+0.9399_{(-28.37)} \mathrm{B}\right) \mathrm{a}_{\mathrm{t}}
$$

Both cases show the influence of the profits obtained by the farmer in the three years prior to the harvest and marketing of the crop. Empirical results that consider real data jointly with both types of forecasted values in both previous models are shown in

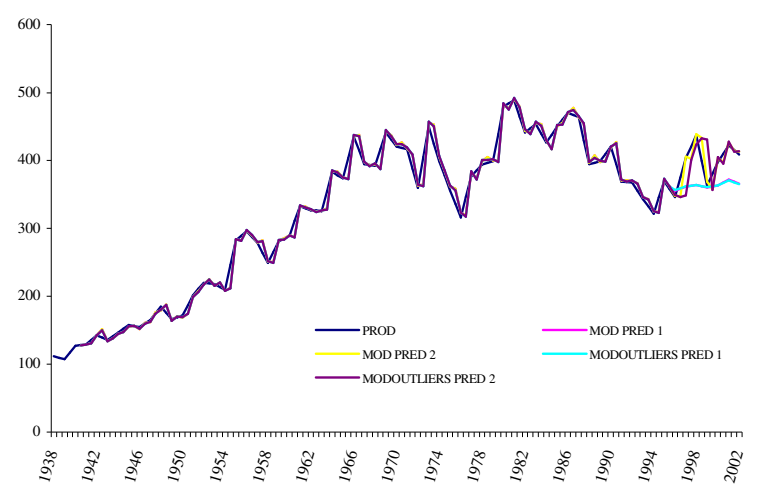

Fig. 1: Production (Benefit)

Fig. 1. These results are quite similar quantitatively and even the same qualitatively as the ones discuss earlier.

Therefore, the higher production costs of the Canarian banana and increasing competition from foreign production do not seem to have conditioned the Canarian banana output evolution as much as it could have in recent decades.

In any case, farmer income -including the European banana subsidies from 1993 to maintain current compensation payments- seems to be the essential variable to explain the most recent Canarian banana output evolution.

Including the cost (ii): a bivariate causal TF model for production and average production cost: The following causal TF model with jointly stationary variables is now considered:

$$
\mathrm{y}_{\mathrm{t}}=\alpha+\sum_{\mathrm{i}=0}^{15} \mathrm{v}_{\mathrm{i}} \mathrm{z}_{\mathrm{t}-\mathrm{i}}+\mathrm{N}_{\mathrm{t}}
$$

A unidirectional dynamic relationship $z_{t} \rightarrow y_{t}$ can be confirmed.

The corner method identifies a rational model with orders $(0,6,2)$. Estimating and deleting non-significant parameters yields the following representation:

$$
\begin{aligned}
& \mathrm{y}_{\mathrm{t}}=\frac{-0.3781_{(-2.31)}+0.9370_{(4.84)} \mathrm{B}^{6}}{1+0.0860_{(-2.68)} \mathrm{B}+0.8342_{(18.17)} \mathrm{B}^{2}} \mathrm{z}_{\mathrm{t}}+ \\
& \left(1+0.7892_{(-8.43)} \mathrm{B}-0.3876_{(3.28)} \mathrm{B}^{2}-0.3555_{(3.61)} \mathrm{B}^{3}\right) \mathrm{a}_{\mathrm{t}}
\end{aligned}
$$


The autocorrelation function for the noise term exhibits a white noise process.

Fig. 2 shows model fitting and forecasted values. Observe how the one-step ahead forecasts made from 1995 appear more reliable in the medium term.

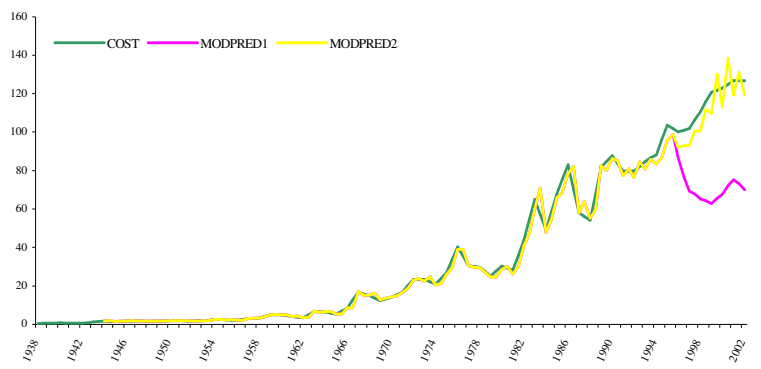

Fig. 2: Cost (Production)

Including the cost (iii): a multivariate causal TF model for production with two inputs (income and cost): The dynamic relationship between the three variables in question is shown through a multivariate time series model. Previous results can be found in ${ }^{[20]}$.

Next we consider the TF model for stationarity processes with one output and two inputs:

$$
\mathrm{z}_{\mathrm{t}}=\sum_{\mathrm{i}=0}^{4} \mathrm{w}_{\mathrm{i}} \mathrm{x}_{\mathrm{t}-\mathrm{i}}+\sum_{\mathrm{i}=0}^{8} \mathrm{v}_{\mathrm{i}} \mathrm{y}_{\mathrm{t}-\mathrm{i}}+\mathrm{N}_{\mathrm{t}}
$$

The existence of a one-way causal dynamic relationship $\mathrm{x}_{\mathrm{t}}, \mathrm{y}_{\mathrm{t}} \rightarrow \mathrm{z}_{\mathrm{t}}$ and the non-presence of autocorrelation between the input series can be confirmed.

Having studied the noise term structure and estimated with SCA the IRF for each input variable, the corner method leads finally to the model:

$$
\begin{aligned}
& \mathrm{z}_{\mathrm{t}}=0.1091_{(2.81)} \mathrm{B}^{4} \mathrm{x}_{\mathrm{t}}+0.0460_{(1.58)} \mathrm{B}^{2} \mathrm{y}_{\mathrm{t}} \\
& +\left(1+0.6798_{(-13.15)} \mathrm{B}-0.3526_{(5.74)} \mathrm{B}^{2}\right) \mathrm{a}_{\mathrm{t}}
\end{aligned}
$$

which considers the influence on production of the income received by the farmer in the three previous years and of production costs from the two previous years. Fig. 3 shows the fit for models (3) and (4) until 1995 , along with the two types of forecasts mentioned above.

Outlier detection only produced one abnormal observation in 1955, with the re-estimated model being basically the same.

The parameters in model (4) allow us to conclude that the banana farmer considers his income as a more relevant variable than production costs. That is why we return to the bivariate Production-Income TF model, but now including the expectations for future earnings.

The dynamic specification of a non-causal TF model implies that assumptions need to be generalised and that the dynamic identification procedures proposed to date in the causal context must be extended.

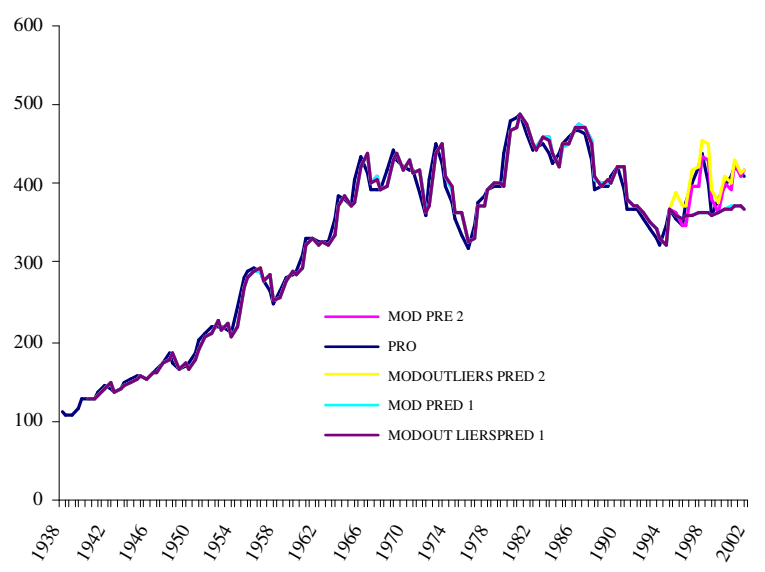

Fig. 3: Production(Income, Cost)

\section{BANANA PRODUCTION TF MODELS WITH INCOME EXPECTATIONS}

A non-causal TF model is proposed to analyse the dynamic relationship between banana production and farmer income in the Canary Islands. We consider historical data including production, income and expectations of future income. An important year during our survey from 1938-1997 is 1993, when the European Union introduced a mechanism of compensatory aid to guarantee the subsistence of the banana sector.

A sensitivity analysis is carried out which considers different theoretical schemes for the compensatory aid expectations from 1997. Other aspects of this analysis can be seen in ${ }^{[18,20]}$. We identify a bivariate TF model with expectations relating Production and Income starting from the particular case:

$$
\mathrm{z}_{\mathrm{t}}=\sum_{\mathrm{i}=-12}^{12} \mathrm{v}_{\mathrm{i}} \mathrm{B}^{\mathrm{i}} \mathrm{x}_{\mathrm{t}}+\mathrm{N}_{\mathrm{t}}
$$

Specifically, four theoretical hypotheses involving income expectations are considered using 1993 as the starting date of the compensatory aid, $x_{t}^{\prime}=x_{t}^{*}, t \leq 1992$, $x_{t}^{\prime}=x_{t}^{* *}, t \geq 1993$. The four series differ in how $x_{t}^{* *}$ is generated and that includes income expectations from 1997 (Fig. 4). 
Case 1: The banana grower expects stable earnings to continue throughout the next decade. In this case, according to the T-table method, the final estimated model is:

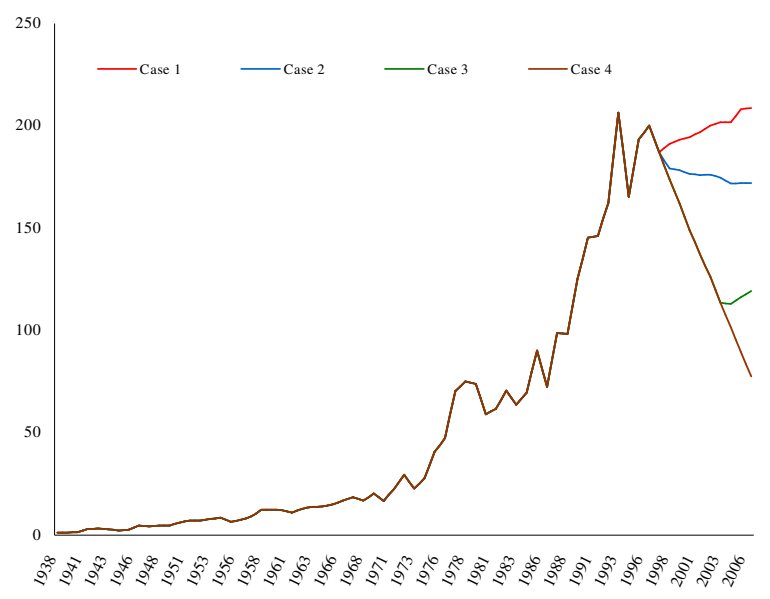

Fig. 4: Income data 1938-1997 and income expectations since 1997 (including Compensatory Aid)

$$
\begin{aligned}
& \mathrm{z}_{\mathrm{t}}=\left(0.2001_{(4.07)}+0.1296_{(2.69)} \mathrm{B}\right) \mathrm{B}^{-7} \mathrm{x}_{\mathrm{t}} \\
& +\left(1+0.8776_{(11.32)} \mathrm{B}-0.1153_{(1.48) \mathrm{B} 2)} \mathrm{B}^{2}\right) \mathrm{a}_{\mathrm{t}}
\end{aligned}
$$

Case 2: The banana grower expects earnings to diminish according to the European Union's decision to reduce costs. In this case:

$$
\begin{aligned}
& \mathrm{z}_{\mathrm{t}}=\frac{0.1661_{(3.00)}}{1-0.5417_{(3.62)} \mathrm{B}^{2}} \mathrm{~B}^{-7} \mathrm{x}_{\mathrm{t}}+ \\
& \left(1+0.7589_{(8.81)} \mathrm{B}-0.2469_{(2.89)} \mathrm{B}^{2}\right) \mathrm{a}_{\mathrm{t}}
\end{aligned}
$$

Case 3: The banana grower expects that after a crisis period earnings will return to an acceptable level. The chosen model is:

$$
\begin{aligned}
& \mathrm{z}_{\mathrm{t}}=\frac{0.1645_{(3.06)}}{1-0.5543_{(3.86)} \mathrm{B}^{2}} \mathrm{~B}^{-7} \mathrm{x}_{\mathrm{t}}+ \\
& \left(1+0.7342_{(8.94)} \mathrm{B}-0.2770_{(3.41)} \mathrm{B}^{2}\right) \mathrm{a}_{\mathrm{t}}
\end{aligned}
$$

Case 4: The banana grower is uncertain when the crisis will end. In this pessimistic context, the resulting model is:

$$
\begin{aligned}
& \mathrm{z}_{\mathrm{t}}=\frac{0.1649_{(3.03)}}{1-0.5480_{(3.60)} \mathrm{B}^{2}} \mathrm{~B}^{-7} \mathrm{x}_{\mathrm{t}}+ \\
& \left(1+0.7959_{(10.29)} \mathrm{B}-0.2129_{(2.82)} \mathrm{B}^{2}\right) \mathrm{a}_{\mathrm{t}}
\end{aligned}
$$

In all four cases we can observe the influence of the farmer's expectations for his income in three or four years on each year's production.

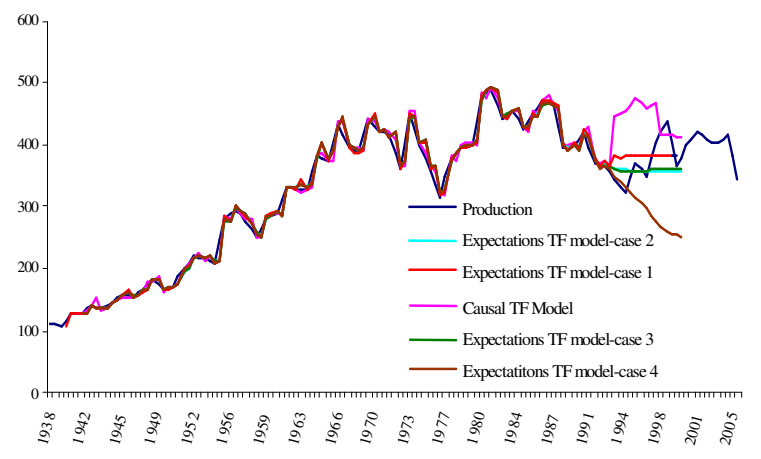

Fig. 5: Models for banana production

In Fig. 5, fitting and predictive performance of the four alternative non-causal TF models and the two causal TF formulations are illustrated. We observe that all specifications provide a satisfactory response from the perspective of fitting to banana output data. However, the TF models with expectations offer better predictions in the short-term.

Case 1 is the most desirable, although it implies reducing banana output. However, it could help prevent the overproduction that occurred in the final years of our survey period. Cases 2 and 3 may be considered the least realistic but they reflect the optimism of the banana grower. Case 4, in which the farmer's income depends exclusively on the market price, highlights the threat to the subsistence of the sector, in which approximately half of current production would be lost and serious economic, social and ecological consequences would result.

\section{CONCLUSIONS}

In general, the problems facing the banana sector in the Canaries are very real and worrysome to all involved.

The economic, social and environmental effects of banana production in the Canary Islands are of general concern, as stated in EU legislation: <<Local banana production is an essential element of the environmental, social and economic balance of the rural areas in the outermost regions of the Union (Guadeloupe, Martinique, the Azores, Madeira and the Canary Islands) $>>{ }^{[26]}$. 
Nowadays the Canarian banana, which is transported along regular shipping routes between the producing regions to Europe, has strong competition in its own European market, especially from Latin American imports where lower labour wages and reduced unit input and shipping costs prevail. However, thanks to the shorter distances between the place of production and the European consumer market with respect to other growing locations, EU consumers can enjoy the qualities of the Canarian banana, which, in addition to those characteristic of the species, include a higher degree of maturation on the plant, resulting in more intense flavour and aroma.

Faced with this dilemma, European payments via compensatory aid have become an essential protection mechanism to guarantee production and farmer income, which must conform to the framework of the World Trade Organization (WTO). Without this aid, the net profit derived from selling the fruit at market price would be nearly zero.

Still, its application over more than a decade has shed light on certain drawbacks such as, for example, the fact that the calculation of the aid, based of Community average prices does not adequately take into account the particularities of each of the producing regions. Linear production quotas caused overproduction in certain areas, which led to a study of different compensation schemes for offsetting the resulting income losses. Although the above aid was limited to a maximum quantity for all producing regions, there is no budget ceiling. Likewise, the mechanism for limiting the production quantity to be subsidised has led to situations in which export companies, once the freight, packaging and shipping costs have been discounted, are actually billing the producers.

One of the goals of the current reform is to keep producers from being artificially isolated from market trends, since the aid automatically compensates for price changes.

In this paper we have presented various models that relate production, profit and certain production costs. According to the methodology proposed in dynamic time series modelling, we identify the income as the essential variable to explain the evolution of banana production in the Canary Islands and assure the future subsistence. We used the models to make an ex post comparison of the production obtained for the quantity produced with the actual production from previous years, though they could also be used to make an ex ante sensitivity analysis of the possible effects of different economic regulations. Present results validate the FAO report ${ }^{[27]}$, according to which the prices used are decisive and influence the results of every analysis. The methodology presented is capable of accounting for the effect of previous income, of certain incurred costs and of the farmer's expectations for his future income on current production. We observe that all specifications provide a satisfactory response from the perspective of fitting to banana output data. However, the TF models with expectations offer better predictions in the short-term. The importance of the farmer's future income expectations is evident in all four cases.

If the European Union is forced to remove protective tariffs, large scale banana production may disappear within decades.

From a strictly economic standpoint, the opening up of other markets outside the mainland, whether in the European Union or beyond, would be of interest, as would reinforcing demand through the use of constant and on-going direct publicity campaigns, as is done now in those places and seasons where banana consumption is low.

In this sense, some markets remain attached to a supply structure that has changed little since CMOB went into effect. Spain thus made intense marketing efforts and succeeded in persuading Spanish and other consumers to continue opting for bananas from the Canary Islands.

Another key element is the restructuring of those businesses involved in the production and marketing of bananas so as to reduce their degree of fragmentation and conflicting strategies, and unify their brands and quality criteria to better manage the joint marketing of the Canarian crop.

It would be beneficial to explore the possibility of establishing aid linked not to output or to prices, but instead aimed at (a) promoting certain banana categories and species (traditional or new) or (b) "rewarding" long established plantations for their help in maintaining traditions and the landscape.

Also worth mentioning are social considerations which serve to preserve rural populations, maintain the landscape, and halt the erosion and urbanization of farm land.

Another quite important feature of EU bananas, and in particular those of the Canary Islands, is the limited use of pesticides: the number of authorised pesticides is only $30 \%$ of those used worldwide for banana production. A very substantial effort has been made in recent years to reduce the amount of pesticides used in the EU by $40 \%$. Also, according to ${ }^{[27,28]}$, there are some pests and diseases, for example, black sigatoka, the most damaging disease of modern banana production, which can be found all over the world with 
the exception of the Canary Islands. Within this context, the production and consumption of ecological products should be encouraged as a way to promote socially natural and environmental values, as should a greater presence of bananas in gastronomy, not just as a fruit, but as a key ingredient in non-perishable prepared goods for both domestic consumption and for export.

It would be necessary to raise the tourist industry's awareness of the need to collaborate in maintaining the banana and farming industries in general, given their influence on preserving both landscape and traditions, and to develop the link between agriculture and rural tourism and related activities.

In general, the regulations, whatever their motivation, must be drafted with those involved in mind (producers, exporters, importers and consumers both in and out of the EU). Even so, they will always lead to controversy of a political and economic nature. As stated in ${ }^{[27]},<<\ldots$ the wide diversity of stakeholders and their conflicting interests makes the search for a consensus on a single tariff extremely difficult...It seems unlikely that there exists a tariff equivalent that would maintain the status quo in all regards. A single policy instrument is not likely to be sufficient to preserve the interests of all the stakeholders. From a policy perspective, it may be preferable to use not just one, but several policy instruments >>.

Finally, there is an obvious need for a greater flow of data to society, and to the researcher in particular. The data available are far from satisfactory and the issue of inserting into this methodology other production costs, especially labour, and marketing costs, along with intermediate profits along the supply chain from the islands to the final consumer, is still to be addressed.

We are, even so, compelled to explore other means of subsidy, aside from any protectionist aid the EU may establish in the future, and the results from this work have provided us with the necessary incentive.

\section{REFERENCES}

1. Thagesen, R. and A. Matthews, 1997. The EU's common banana regime: An initial evaluation. J. Common Market Stud., 35 (4): 615-627.

2. Borrell, B., 1997. Policy-making in the EU: The bananarama story, the WTO and policy transparency. Aust. J. Agric. Resour. Econ., 41(2): 263-276.

3. Guyomard et al., 1999. Impact of the common market organization for bananas on European Union markets, International Trade and Welfare. J. Policy Model., 21(5): 619-631.
4. McCorriston, S., 2000. Market Structure issues and the evaluation of the reform of the EU banana regime. World Econ., 23 (7): 923-937.

5. Florido, C. et al., 2002. Firm behaviour and interaction in the European banana market: 19601993. J. Agric. Econ., 53 (2): 319-344.

6. Chaussebourg, C. (sub-editor for FARM), November, 2005. The International banana Trade: Between evolution and revolution. Foundation for Agriculture and Rural Areas around the World Briefing.

7. Anania, G., 2006. The 2005 WTO arbitration and the new EU import regime for bananas: A cut too far? Eur. Rev. Agric. Econ., 33 (4): 449-484.

8. Liu, L.M. and G. Hudak, 1992. Forecasting Time Series Analysis Using the SCA Statistical System. Chicago, Illinois 60607-3528, USA.

9. Gil, M.C. and C. González, 1997. Modelización Racional de Series Temporales No Causales: Algunas Propuestas de Caracterización Dinámica. Estudios de Economía Aplicada, 8: 77-107.

10. Lii, K., 1985. Transfer function model order and parameter estimation. J. Time Series Anal., 6 (3): 153-169.

11. Baker, G.A. Jr. and P. Graves-Morris, 1996. Padé Approximants. 2nd Edn. Encyclopedia of Mathematics and its Applications, 53, Cambridge University Press.

12. Bultheel, A., 1987. Laurent Series and their Padé Approximations, Birkhaüser, Basel/Boston.

13. Liu, L.M. and D.M. Hanssens, 1982. Identification of Multiple Inputs Transfer Function Models. Commun. Stat. Theor. Math. A11, 3: 297-314.

14. Berlinet, A. and C. Francq, 1994. Identification of a univariate arma model. Comput. Stat., 9: 117-133.

15. Tsay, R.S., 1985. Model Identification in Dynamic Regression (Distributed Lag) Models, J. Bus. Econ. Stat., 3 (3): 228-237.

16. Claverie, P., D. Szpiro and R. Topol, 1990. Identification des Modèles à Fonction de Transfert: La Méthode Padé-Transformée en z, Annales d'Economie et de Statistique, $17:$ 145-161.

17. González, C., V. Cano and M.C. Gil, 1995. The epsilon-algorithm for the identification of a transfer-function model: Some applications. Numerical Algorithms, 9: 379-395.

18. Gil, M.C. and C. González, 2002. La Producción del Plátano en Canarias y las Expectativas del Agricultor sobre la Ayuda Compensatoria. Revista Española de Estudios Agrosociales y Pesqueros, 194: 127-146. 
19. González, C. and M.C. Gil, 2003. Padé Approximation in Economics. Numerical Algorithms, 33 (1-4): 277-292.

20. González, C., M.C. Gil and C. Pestano, 2007. Some algorithms to identify rational structures in stochastic processes with expectations. J. Math. Stat., 3 (4): 268-276.

21. Beguin, J.M., C. Gourieroux and A. Monfort, 1980. Identification of a Mixed Autoregressive-Moving Average Process: The Corner Method, Anderson, O.D. (Ed.). Time Series, North-Holland, Amsterdam, pp: 423-436.

22. Boletín Mensual de Estadística Agraria, Edited by Ministerio de Agricultura, Pesca y Alimentación (MAPA), Spain.

23. Servicio de Estadística y Estudios, Consejería de Agricultura, Pesca y Alimentación del Gobierno de Canarias.

24. Nuez, J.S., 2002. El Mercado Mundial de Plátanos y las empresas productoras en Canarias, 18702000. Tesis Doctoral, Universidad de La Laguna, Spain.
25. Press, W.H. and G.B. Rybicki, 1993. Large-Scale Linear Methods for Interpolation, Realisation and Reconstructing of Noisy, Irregularly Sampled Data. In: Time Series Prediction: Forecasting the Future and Understanding the Past. Weigend, A.S. and N.A. Gershrnfeld (1993) Addison-Wesley Publishing Company.

26. MEMO/06/335, September 2006. Banana CMO Reform, Brussels.

27. FAO, 2004. Is there a tariff-only equivalent to the EU tariff rate quota regime? Insights from economic analysis. FAO Trade Policy Technical Notes on Issues Related to the WTO Negotiations on Agriculture, No. 3: Bananas.

28. FAO, 2005. Banana Projections 2010, Committee on Commodity Problems Intergovernmental Group on Bananas and Tropical Fruits Meeting, Tenerife, CCP. BA/TF 03. 